ISSN 2237-258X

\title{
A ERA VARGAS EM MATO GROSSO: O JORNAL “A CRUZ” E A REPRESENTAÇÃO DO IDEAL DE EDUCAÇÃO
}

\author{
The vargas' era in Mato Grosso: "THE CROSS" journal and the representation of ideal \\ Education
}

\section{La era vargas en Mato Grosso: el periodico "LA CRUZ" es la representacion del ideal de Educação}

Regiane Cristina Custódio*

\begin{abstract}
Resumo
Este artigo é um exercício de observação do modo como, por meio do Jornal A CRUZ, um periódico da Liga Social Catholica Brazileira de Matto-Grosso (de ampla circulação em Cuiabá, capital do estado) se disseminava o ideal de educação em Mato Grosso, bem como no Brasil, em sua totalidade. No contexto de ocupação da Amazônia e Centro-Oeste, através da "marcha para o Oeste" (1938), fala-se aqui, para além das transformações físicas da arquitetura das obras oficiais de Cuiabá, sobre uma expressiva representação de educação com o propósito de produzir um cidadão moderno e civilizado para viver em uma sociedade que deveria superar o atraso e avançar em direção aos padrões da modernidade que se instaurava naquele período. No contexto de ocupação da Amazônia e Centro-Oeste do Brasil, a cidade passou a desempenhar uma função educativa no processo de modernidade que se manifestava no estilo de vida urbano, ou seja, "são nas cidades que se promove o aprendizado para a civilidade e sociabilidade" conforme assinalou Buzato (2013, p. 1). E ao aprender a viver para a sociabilidade o cidadão se habilitava também, à convivência urbana.
\end{abstract}

PALAVRAS-CHAVE: Era Vargas. Educação. Jornal A CRUZ. Mato Grosso. Brasil.

\begin{abstract}
This article is an exercise in observing the way in which, through the newspaper THE CROSS, a journal of Mato Grosso Catholic League of Brazil (with wide circulation in Cuiabá, capital of the state), the ideal of education in Mato Grosso was disseminated, as well as in Brazil, in its entirety. In the context of the occupation of Amazonia and Midwest, through the "March to the West" (1938), it is stated here, in addition to the concrete transformations of the architecture of the official buildings of Cuiaba, about an expressive representation of education with the purpose of producing a modern and civilized citizen to live in a society that should overcome the backwardness and advance towards the standards of the modernity that was established in that period. In the context of the occupation of the Amazon and Midwest of Brazil, the city began to play an educational role in the process of modernity manifested in the urban lifestyle, that is, "it is in the cities that learning is promoted for civility and sociability "as pointed out by Buzato (2013, p.1). And in learning how to live for sociability, the citizen was also able to live in urban coexistence.
\end{abstract}

KEYWORDS: Vargas era. Education. Newspaper THE CROSS. Mato Grosso. Brazil

\footnotetext{
* Doutora em Educação. Professora da Universidade do Estado de Mato Grosso, Campus Universitário de Tangará da Serra, professora do Profhistória UNEMAT/Cáceres-MT. Membro do grupo de pesquisa: Cultura, Política e Sociedade. E-mail: rccustodius@gmail.com; regianecustodio@unemat.br
} 


\section{Resumen}

Este artículo es un ejercicio de observación del modo como, por medio del periódico La Cruz, un periódico de La liga Social Católica Brasileña de Mato Grosso (de amplia circulación en Cuiabá, capital del estado) se diseminaba el ideal de educación en Mato-Grosso, así como en Brasil en su totalidad. En el contexto de ocupación de Amazonas y Centro Oeste, a través de la marcha para el Oeste (1938), se decía que además de las transformaciones físicas de la arquitectura de las obras oficiales de Cuiabá, había una representación de educación, con el propósito de crear un ciudadano moderno y civilizado para vivir en una sociedad que debería superar el atraso y avanzar en dirección a los patrones de modernidad que se instauraba en aquel período. En el contexto de ocupación de Amazonas y Centro Oeste de Brasil, la ciudad pasó a desempeñar una función educativa en el proceso de modernidad que se manifestaba en el estilo de vida urbano, o sea "son las ciudades las que promueven lo aprendido en la civilización y sociedad" conforme señalo Buzato (2013, p. 1). Y al aprender a vivir en sociedad el ciudadano se habilitaba también, a la convivencia urbana.

PALABRAS CLAVE: Era Vargas. Educación. Periódico LA CRUZ. Mato Grosso. Brasil.

\section{INTRODUÇÃO}

Este artigo é um exercício de observação do modo como, por meio do Jornal $A$ CRUZ, órgão da Liga Social Catholica Brazileira de Matto-Grosso (um jornal católico de ampla circulação em Cuiabá, capital de Mato Grosso) se disseminava o ideal de educação em Mato Grosso, bem como no Brasil, em seu conjunto. Em algumas edições do jornal é possível observar que a responsabilidade pela "formação de personalidades disciplinadas e conscientemente orientadas para um fim alevantado" ( $A C R U Z, 2$ março, 1941) cabia às mulheres, em especial, às mães. A elas se atribuía a incumbência de formar os jovens, filhos e filhas para viver em uma sociedade que deveria superar o atraso e avançar em direção aos padrões da modernidade que se instaurava naquele período, marcado em âmbito nacional, por um ideário desenvolvimentista.

\section{A educação em Mato Grosso durante o Estado Novo (1937-1945)}

Para refletir sobre a educação em Mato Grosso durante o Estado Novo, é importante lembrar-se da trajetória política de Getúlio Dornelles Vargas que por quatro vezes esteve na Presidência da República. De 1930 a 1934, no Governo Provisório; de 1934 a 1937 no governo constitucional; de 1937 a 1945, no Estado Novo; e de 1951 a 1954, por meio de voto direto, eleito pelo povo brasileiro. Marcadamente neste texto, o foco recai sobre o período nomeado como Estado Novo, com suas especificidades.

Gino Francisco Buzato (2013) ao escrever o texto": "As transformações urbanas em

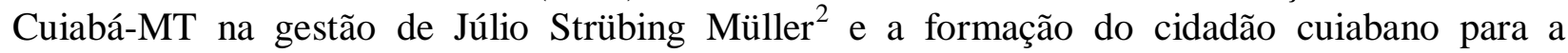

\footnotetext{
${ }^{1}$ Texto apresentado no VII Congresso Brasileiro de História da Educação: “Circuitos e Fronteiras da História da Educação no Brasil”, que aconteceu na Universidade Federal de Mato Grosso/UFMT, em Cuiabá, no ano de 2013.

${ }^{2}$ Júlio Strubing Müller nasceu em Cuiabá no dia 6 de janeiro de 1895, filho de Júlio Frederico Müller e de Rita Correia Müller. [...] Estudou humanidades no Colégio Salesiano de Cuiabá, cursou a Academia de Direito da mesma
} 
modernidade (1937-1945)" analisa a formação do cidadão cuiabano para a modernidade relacionada às transformações urbanísticas promovidas pela gestão do interventor Júlio Müller, entre os anos acima citados. O foco principal de sua reflexão recai sobre o processo de modernização de Cuiabá nesse período, e assim, relaciona-o com a formação de novos hábitos e práticas sociais esperados pelos governantes de seus habitantes em uma realidade urbana envolta em valores tradicionais muito mais representativos ao meio rural.

Durante a gestão do interventor Júlio Strübing Müller, foram construídos o Hospital Geral, o Colégio Estadual de Mato Grosso e a ponte Júlio Müller que liga Cuiabá a Várzea Grande. Ainda outras fundações ocorreram, o Departamento Estadual de Estatística, o Departamento de Saúde Pública, além da reforma da imprensa estadual. Ainda durante sua gestão, em setembro de 1943 foram desmembrados de Mato Grosso os territórios federais de Guaporé (hoje Rondônia) e Ponta Porã. Este último, contudo, voltou a integrar o estado por força da Constituição de 1946.

Gino Francisco Buzato (2013) destacou as transformações vividas pelo Brasil das décadas de 1930 e 1940 marcadas nacionalmente pelo ideário desenvolvimentista implementado pelo Estado Novo de Getúlio Vargas. Segundo as palavras do autor:

Uma onda de modernização ocorreu em várias cidades brasileiras que causaram impactos pelas transformações físicas e pelas representações de educação impregnadas nas práticas urbanas no propósito de produzir o cidadão moderno e civilizado. Nesse sentido, as cidades são tomadas como exemplo do ideal moderno. São nelas que se criam novas concepções culturais e que se evidencia a importância da ciência e do progresso distanciando-se, cada vez mais, das mentalidades tradicionais forjadas no ambiente rural, passando esse, a representar o que há de mais retrógrado e atrasado (BUZATO, 2013, p. 1)

Naquele contexto, a cidade passou a desempenhar uma função educativa no processo de modernidade que se manifestava no estilo de vida urbano. Buzato analisa que "são nas cidades que se promove o aprendizado para a civilidade e sociabilidade". E uma vez aprendendo a viver para a sociabilidade o cidadão está habilitado à prática do direito à convivência urbana. Sob tal perspectiva, o urbano se constitui num cenário "dinâmico de formação, uma vez que a civilidade

cidade, pela qual se formou. [...] Em consequência da vitória da Revolução de 1930, foi nomeado prefeito de Cuiabá, tendo assumido também a chefia de polícia e a secretaria geral do estado. Em 1933, decidida a convocação de eleições para a Assembleia Nacional Constituinte, criaram-se em todos os estados partidos representando os objetivos doutrinários da Revolução de 1930. Em Mato Grosso, foi fundado o Partido Liberal Mato-Grossense, liderado pelo interventor Leônidas Antero de Matos. Júlio Müller participou da primeira comissão executiva do novo partido. No pleito de outubro de 1934, elegeu-se deputado à Assembleia Constituinte estadual que, além de preparar a Constituição do estado, tinha também a incumbência de eleger o governador de Mato Grosso e dois representantes do estado ao Senado Federal. Desse modo, no dia 7 de setembro de 1935, Mário Correia da Costa foi eleito para chefiar o Executivo mato-grossense. Em 13 de setembro de 1937, com a morte de Correia da Costa, Júlio Müller foi eleito governador pela Assembleia Legislativa, com mandato até 15 de agosto de 1939. Tomou posse no dia 4 de outubro e administrou o estado como governador constitucional por pouco mais de um mês, pois a implantação do Estado Novo no dia 10 de novembro daquele ano suspendeu todos os mandatos eletivos do país. Entretanto, no dia 24 de novembro foi reconduzido ao governo de Mato Grosso, desta vez como interventor federal no estado. [...] Cinco dias depois da deposição de Getúlio Vargas (29/10/1945), Júlio Müller foi destituído da interventoria. Morreu em Cuiabá, no dia 4 de março de 1977. Foi casado com Maria de Arruda Müller, com quem teve seis filhos. Informações disponíveis em: 〈http://www.fgv.br/cpdoc/acervo/dicionarios/verbete-biografico/julio-strubing-muller〉 Acesso em: 21 nov. 2017. 
se aprende a partir das relações entre os cidadãos e desses com o ambiente construído impregnado de significados" (BUZATO, 2013, p. 1).

Segundo Lacerda (2004) as transformações urbanas voltadas à modernização da cidade que ocorreram na capital mato-grossense durante o Estado Novo estavam vinculadas a um conjunto de prédios denominado de "Obras Oficiais", que promoveu a construção de diversas edificações que, ao inserir alguns signos da modernidade na paisagem urbana de Cuiabá, provocou uma certa descontinuidade no estilo de vida da sociedade local, o que contribuiu para a formação de uma nova sensibilidade em seus habitantes (LACERDA, 2004 apud BUZATO, 2013).

Eslânia Fernandes Gomes (2011) ao refletir sobre as construções sociais do moderno no nordeste brasileiro considera que o projeto de modernidade visava, segundo os ideais iluministas, buscar o progresso humano através do desenvolvimento intelectual do homem, ampliando sua mentalidade a partir das organizações sociais para que atuassem de modo racional. Sob tal perspectiva, a autora considera que ao ampliar o intelecto e pensar de maneira crítica, o homem descobriria a sua própria racionalidade. A busca pelo conhecimento poderia forjar o progresso. Assim, pode-se dizer que a modernidade se caracterizou, como destaca a autora, por intenções virtuosas, pois pretendia atingir a todos de forma abrangente. Era um plano de melhoria que aspirava redefinir o indivíduo e, assim também, suas relações com o mundo. Mais que uma mudança estética ou comportamental, pretendia transformar as mentalidades, fazendo o ser humano necessitar ser moderno.

Para tanto, era necessário criar situações que suprimissem a ruptura com o antigo. Era urgente que se produzisse um incômodo nas pessoas como se quem não pretendesse se modernizar, seria tão irracional que não perceberia como a modernização seria necessária, observa a autora. Assim, foi na ideia emergencial de necessidade de melhorias na vida em sociedade que a modernidade se apoiou. Além das transformações físicas, levando em conta a arquitetura das obras oficiais, ocorreu uma intensa representação de educação que tinha como propósito produzir um cidadão moderno e civilizado. E tal ideia de educação do homem da modernidade estava ligada, além de se considerar a educação institucional, principalmente, com a educação doméstica, ou seja, aquela recebida no seio da família.

A educação do cidadão que estava se formando para viver a modernidade buscava moldálo de acordo com as configurações da vida urbana. E, nesse sentido, o Jornal $A C R U Z$, órgão da Liga Social Catholica Brazileira de Matto-Grosso, (um jornal católico de ampla circulação em Cuiabá) parece ter tido uma grande importância no contexto da Cuiabá daquele período. Os excertos extraídos de $A C R U Z$ que constam nesta escrita foram todos retirados da secção referente ao ano de 1941.

O periódico A CRUZ foi um meio de comunicação importante na sociedade cuiabana do início do século XX. Foi publicado desde a primeira década até meados dos anos 1950. Esse periódico era editado pelo Seminário Episcopal da capital, Cuiabá, e os artigos/matérias nele veiculados eram escritos por padres, bispos, tinha também na equipe uma correspondente internacional e pessoas do meio religioso católico. $\mathrm{O}$ jornal que era publicado quinzenalmente informava seus leitores, com notícias sobre os acontecimentos da cidade, do estado de Mato Grosso, do país como um todo, trazia também informes sobre aniversários, casamentos e notas de falecimentos, além de informações sobre festas religiosas e publicação de anúncios comerciais e, claro, sobretudo matérias referentes à Igreja Católica, contemplando colunas e editoriais sobre 
como deveria ser a conduta dos fiéis católicos, principalmente das mulheres (ZIMMERMANN, $2013)^{3}$.

A edição de 02 de março de 1941 trouxe um texto que tinha como título: "A mãe do homem de amanhã”. No referido texto o autor, José Ramos Rosa, falava sobre o mundo daquele momento como algo desolador e que o amanhecer era incerto diante daquela geração que valorizava muito mais a promiscuidade do que a honra e os bons costumes. Segundo ele, a sociedade naquele momento valorizava muito mais a mentira do que a verdade e as forças do mal realizavam a inversão de todos os valores. Era necessário, diante daquele quadro de amanhecer incerto pelo qual a sociedade estava passando que surgisse um novo homem que estivesse mais de acordo com o novo cenário que estava se formando. Segundo o autor, o "homem de amanhã", não poderia mais continuar como estava, pois, esse homem estava segundo suas palavras:

[...] espicaçado pelo egoísmo, manietado ${ }^{4}$ pela paixão; incapaz de perceber na pequenez de sua alma franzina a grandeza e a transcendência de um ideal. Cresce por aí, sem ideal e sem crença, agitando-se em torno às mesas de "cafés", a geração que cumpre formar o corpo social de amanhã. Nos teatros e cinemas "se orienta e se educa", ou sôfrega sorve os princípios que lhe nortearão a existência, na literatura fútil e rica, quando não pornográfica, dissolvente e deletéria que abarrota o mercado. Um olhar ao redor ou mesmo dentro de cada um de nós, nos mostra que, personalidades disciplinadas e conscientemente orientadas para um fim alevantado - rareiam sempre mais. Na razão inversa, a mediocridade se espraia e se consagra (A CRUZ, 02 de março de 1941, p. 2).

Apesar do cenário que se mostrava pouco promissor havia uma solução, e essa solução parecia estar nas mãos das mulheres, quer dizer, nas mãos da mãe e que fosse uma mãe cristã. Na sequência do texto de José Ramos Rosa:

\begin{abstract}
"Mas nem tudo está perdido", dizia um pensador, a mãe cristã se sacrifica na formação da família e dessa energia oculta e desprezada em nossos dias, há de se levantar de novo a sociedade, quando esta enfim compreender aonde a pode levar o renascimento pagão dos nossos tempos. No lar começa a sociedade. Mas nem todas as mães tem persuasão da responsabilidade que lhes cabe na delicada missão de formar a alma da criança. Fogese-lhes da mente que daí sairá o que serão mais tarde, o que fatalmente refletirá no organismo social do futuro com maior ou menor intensidade, a personalidade humana que modelaram (A CRUZ, 02 de março de 1941, p. 02).
\end{abstract}

E o texto segue e o autor descreve a juventude como o momento da vida em que a pessoa sente ferver dentro de si verdadeiras paixões, e, diante de um mundo quase desconhecido, fantástico e misterioso, a juventude "desvia-se da rota" e é justamente, nessa fase da vida em que os jovens estão perdidos e tomados por forças "do mal", que se espera da mãe cristã que possa se fazer presente de maneira mais ativa na vida desse jovem. $\mathrm{O}$ autor prossegue:

\footnotetext{
${ }^{3}$ Segundo a autora "Nas edições dos anos de 1910 a 1915 - período pelo qual sua pesquisa se pautou e o qual analisou o periódico A Cruz transcorreu nas suas páginas uma expressiva preocupação da Igreja em combater e conscientizar o seu público leitor de problemas contemporâneos que pudessem ameaçar o modelo patriarcal das famílias cristãs cuiabanas/mato-grossenses, tendo em vista que o jornal era eivado de representações de um catolicismo conservador e tradicional" (ZIMMERMANN, 2013, p. 43)

${ }^{4}$ Encarcerado, preso, atado, prisioneiro.
} 
Esse período da vida exige sólidas convicções e é ainda às mães, especialmente às mães cristãs, que cabe cimentá-la, apontando às almas jovens, a inconfundível figura de Jesus, o mestre e guia por excelência. [...] A hora que o mundo atravessa é grave, mas - 'nem tudo está perdido" - "Mães cristãs"! a Igreja e o Brasil, de olhos voltados para a geração que desponta, exigem de vós uma enérgica reação. Amanhã, sob a luz de esplêndida alvorada de paz e felicidade, uma sociedade nova, sã, vigorosa e forte, cantará hinos de gratidão, bendizendo tua obra e perpetuando tua memória; ou, então, rebentarão gritos de furor, de ódio e maldição, e os espetros dos que tombaram às margens do caminho, se erguerão para acusar-te, inexoráveis, terríveis, - como causadora de sua perda e de seus fracassos (Lages, Janeiro, 1941. José Ramos Rosa. A CRUZ, 02 de março de 1941, p. $02)$.

Diante do que diz José Ramos Rosa, que atribui às mães a responsabilidade de redenção da sociedade, pode-se indagar: qual o lugar dessas mulheres naquele contexto? Não parece ser o espaço público, mas sim o espaço privado da casa e da família para constituir um lar.

É possível perceber que as notícias que eram direcionadas ao público feminino apresentavam seu objetivo central de uma maneira vigorosa com a intencionalidade de produzir um modelo de conduta moral e cristã-católica imposta com rigor pela Igreja, e as mulheres cuiabanas/mato-grossenses (e todas aquelas que as edições do jornal alcançassem) teriam de exercê-la de maneira rigorosa. A educação moral cristã dos filhos era de total responsabilidade das mulheres. As funções atribuídas a essas mulheres e que estavam associadas a uma postura moral-religiosa eram baseadas no desempenho de papéis restritos ao espaço doméstico e privado no interior das famílias, como os de donas de casa, mães e esposas. Só assim, com o sacrifício da mãe cristã na formação da família se poderia novamente elevar a sociedade a modos de viver mais saudáveis e menos frívolos, além de fazê-la compreender que "o renascimento pagão" daqueles tempos teria de ser eliminado por meio de uma educação cristã-católica.

Um estudo realizado por Semiramis Nahes que deu origem a sua dissertação de mestrado, e posteriormente, foi publicado como livro (2007) com o título: "Revista FON-FON: a imagem da mulher no Estado Novo (1937-1945)", a autora analisou um magazine que circulou de 1907 a 1958 no Brasil, e a partir desse estudo observou que o período intitulado historicamente como Estado Novo (1937/1945) foi um momento em que se enfatizou com bastante insistência a mulher do espaço privado, trazendo com vigor a representação da esposa, da "rainha do lar" como sendo um dos principais colaboradores do Estado. Segundo suas palavras:

[...] a partir do início da Era Vargas, 1930, que a mulher sai das portas das fábricas, da militância, ou seja, do espaço público, persuadida pelo discurso ideológico do Estado que se firmava na idéia do mens sana in corpore sano, programas de aleitamento materno etc. Evidentemente, essa estratégia de retirada da mulher do espaço público e de retorno ao espaço privado do lar fazia parte de um projeto maior, o de um Estado autoritário, que tinha pressa em se estabelecer, unindo, sob forma de apropriação, o antigo discurso voltado para as massas e propagado pelos anarquistas e comunistas dos anos 20, ao discurso direcionado, agora, às elites industriais. Em sua existência, sobretudo durante o Estado Novo, Fon-fon discorreu o tempo todo sobre a mulher - a mulher-criança, a mulher-adolescente, a mulher-filha, a mulher-namorada, a mulhernoiva, a mulher-esposa, a mulher-mãe, a mulher-profissional da saúde, a mulhereducadora, enfim, a mulher do lar, a mulher "ideal" (NAHES, 2007, p. 18). 
A Revista FON-FON, diferente do Jornal A CRUZ foi uma revista brasileira fundada no Rio de Janeiro em 1907. Seu nome era uma onomatopéia do barulho produzido pela buzina dos automóveis ${ }^{5}$.

A CRUZ, por sua vez, era um órgão da Liga Social Catholica Brazileira de MattoGrosso, que segundo Otávio Canavarros (s/d) buscava realizar a política católica no contexto mato-grossense da primeira República. Continha um enfoque cultural e preocupação catequética, doutrinária, buscando travar embates de ideias e valores e evitava as configurações personalísticas e partidárias. Apesar disso, tanto quanto o que Semiramis Nahes (2007) observou no periódico que analisou, é possível apreender, também no jornal $A$ CRUZ que estavam presentes em suas páginas muito dos ideais do Estado Novo, tendo em vista que o ideal de educação preconizado pela igreja se aproximava do ideal de educação necessário para que os cidadãos pudessem, a partir do domínio de suas paixões e do refinamento dos modos, conviver no espaço urbano em configuração naquele período. Era uma espécie de disciplinamento e a educação ideal era a educação doméstica, recebida no seio da família. Somente a educação cristãcatólica seria capaz de construir "personalidades disciplinadas e conscientemente orientadas para um fim alevantado" (A CRUZ, 02 de março de 1941, p. 2).

A edição de $A C R U Z$ de 23 de março de 1941 trouxe um pequeno texto que tinha como título: "A Mãe Cristã", e nele pode-se ler a seguinte inscrição:

A lembrança de uma santa mãe, como suas lições e ensinamentos, vive em nosso coração até o fim de nossa vida; porque traz à nossa mente o amor mais terno, mais desinteressado e por consequência mais sincero. Um filho extraviado poderá dizer, talvez, para abafar seus remorsos: "Minha mãe se enganou"; jamais dirá, porém: "Minha mãe me enganou". "Si a mãe tem por um dever imprimir profundamente sobre a fronte de seu filho o caráter divino, pode estar segura de que o vício jamais o maculará para sempre". Esta é, pelo menos, a observação do conde José de Maistre. Nestes dias tão perturbados, si em cada lar doméstico, junto ao berço, se sentisse pulsar um coração de mãe cristã, isto é, um coração pronto a tudo sacrificar para salvar a alma de seu filho, menor número haveria de mães infelizes e mais famílias abençoadas por Deus. Infelizmente quase não se encontra nas famílias, quem, para salvar uma alma, tenha a força de orar, padecer e esperar... Na verdade, muitos oram, muitos padecem e sofrem, mas bem poucos sabem esperar e perseverar na oração e no sofrimento. A mãe cristã, principalmente, precisa saber, não só orar bem, mas ainda sofrer e esperar bem. Nisso está o segredo da sua força e da sua vitória. (A CRUZ, 23 de março de 1941, p. 3).

Uma vez mais, a mãe cristã é responsabilizada, teria de talvez, viver um tormento, sacrificar-se em prol de seus filhos. Se os filhos não se tornassem bem sucedidos, a "culpa" recairia sobre elas.

Uma das características gerais da imprensa que se caracterizava como feminina (ou ainda em que algumas de suas matérias se direcionavam ao público feminino), fossem jornais ou

\footnotetext{
${ }^{5}$ Sobre esta revista Andréa Silva de Franga (2013) escreveu o seguinte: A Fon-Fon! Foi uma revista ilustrada produzida de 1907 a 1945, no Rio de Janeiro. Era um semanário alegre, politico, crítico e esfuziante, com noticiário avariado, telegrafia sem arame, crônica epidêmica, conforme ela mesma se apresentava. Para Claudio Machado Jr. (2009), a revista Fon-Fon! refletia o sentimento cosmopolita que pairava na capital brasileira e que buscava uma afinidade muito grande com Paris, pois "na década de 1920, o Rio de Janeiro dividia-se entre Hollywood e Paris, num conglomerado de culturas que ditava aquilo que se costuma denominar como modernidade carioca". (MACHADO, 2009, p. 90 apud FRAGA, 2013, p. 73)
} 
revistas, traziam artigos contendo temas sobre moda, educação, cuidado de si e da família, e, principalmente, traziam prescrições sobre a educação dos filhos, bem como da conduta de si e de toda a família, dos filhos e das filhas também (ZIMMERMMANN, 2013).

No artigo escrito por Tânia Zimmermann e Ana Carolina Oliveira Carlos (2013) as autoras informam que também competia às mães de família o papel de selecionar criteriosamente o futuro genro, ou seja, a mãe ajudaria a escolher o marido da filha e o pretendente até poderia ser de outro pertencimento étnico, mas antes de qualquer coisa, tinha de ser da mesma religião, além disso, claro, tinha de ser também honesto e trabalhador de modo que conseguisse sustentar uma família. Em uma edição do Jornal A CRUZ de 1915, por exemplo, lia-se o seguinte enunciado:

Não vai fazendo casar a tua filha com qualquer um, cujos costumes ignoras. Antes a
deixares solteira. Escuta: não terás preconceito de cor. Consulta primeiramente se as
crenças da tua filha combinam com as do noivo; do contrário, será isso um dos primeiros
motivos para graves discórdias futuras. Consulta se é um moço de bom procedente,
temente a Deus, afeito a trabalhos que garantem o futuro de uma família; do contrário,
não dou um ano e estarás com mais trabalhos, despesas e desgosto em casa. [...]. Cuida
da educação dessa menina, faze dela uma boa e piedosa cristã e quando vires com
critério e capacidade suficiente para tornar estado pedirás a Deus que faça com que
possas discernir os bons e maus pretendentes (A CRUZ, 11 jul. 1915, p. 2 apud
ZIMMERMANN, 2013, p. 46).

O texto acima, explica a autora, Zimmermann (2013) foi localizado em uma coluna que se intitulava Cara Irmã e que era publicada esporadicamente nas edições do jornal $A C R U Z$. Era escrita por um homem que assinava como sendo Gil Moreno (e não foi encontrada nas edições do jornal, nem anteriores, nem posteriores, nenhuma menção de quem poderia ser este autor). Tal coluna, segundo Zimmermann (2013), foi publicada por um breve período, de início de abril de 1915, até sua última publicação, em setembro do mesmo ano. A referida coluna expressava diversas situações vivenciadas cotidianamente no interior de uma família católica.

Em alguns momentos do texto, percebe-se algo como se o autor gritasse com suas leitoras num apelo insistente com o objetivo de "conscientizá-las" de sua séria responsabilidade de transformar a sociedade por meio da maneira como conduzia as ações no interior de sua casa e de sua família. O texto tem um movimento interessante na sua construção, pois, ao ler o que está escrito, se tem a impressão que o texto está voltado para a leitora, de uma maneira que a leitora é aproximada do autor de modo a refletir naquelas palavras que haviam sido escritas de modo cuidadoso para atingir a cada uma, para tocar profundamente e chamar à responsabilidade. $\mathrm{O}$ que fica bastante claro nas expressões: "Não vai fazendo casar a tua filha com qualquer um"; "Escuta"; "Consulta"; "Cuida da educação dessa menina". Essas expressões em destaque permitem uma íntima aproximação da leitora com o que era lido. São expressões escritas no singular, como numa tentativa de atingir a cada uma, e assim, sensibilizar para a construção de novas práticas.

No prefácio do livro de Buitoni, Mulher de papel: a representação da mulher na imprensa feminina brasileira, Ecléa Bosi (1981, p. XII) discute a relação entre imprensa e público feminino:

Vós, tu, você: o texto da imprensa feminina sempre vai procurar dirigir-se à leitora, como se estivesse conversando com ela, servindo-se de uma intimidade de amiga. Esse jeito colonial, que elimina a distância, que faz as ideias parecerem simples, cotidianas, 
frutos do bom senso, ajuda a passar conceitos, cristalizar opiniões, tudo de um modo tão natural que praticamente não há defesa (BOSI, 1981, p. XII apud ZIMMERMANN, p. 42)

Importante ainda mencionar no contexto desta escrita, que foi com o advento da Nova História que temas antes recusados pela historiografia passaram a ser considerados nos estudos históricos, inaugurando novas tendências metodológicas para a construção historiográfica. Segundo as palavras de Carlos Antônio Aguirre Rojas (2004):

[...] passaram a investigar a história da família, as tradições e formas de consciência da classe operária, o medo ou os odores, a sensibilidade e as atitudes morais das sociedades, os imaginários populares, o nascimento da ideia do purgatório, a cosmovisão de um moleiro do século XVI, a história da loucura ou da razão nas épocas clássica e moderna, a vida privada e a vida cotidiana, o imaginário trifuncional do feudalismo, a ideia da morte ou da descristianização, a imagem da criança no Antigo Regime, entre muitas outras (ROJAS, 2004, p. 110 apud ZIMMERMANN, p. 42).

Consequentemente, a história das mulheres ganhou visibilidade e espaço no meio intelectual. Ainda algo mais é necessário antes de finalizar este texto, e se refere à utilização da mídia como fonte de análise para a pesquisa histórica, ou para a pesquisa em qualquer outra área do conhecimento no âmbito das Ciências Humanas e Sociais e que podem nos auxiliar a construir leituras de mundo. Esse "algo mais" provém da observação realizada pela pesquisadora Laura Antunes Maciel (2004). Segundo suas palavras:

(...) é preciso refletir sobre nossos procedimentos e os modos como lidamos com a imprensa em nossa prática de pesquisa para não tomá-la como um espelho ou expressão de realidades passadas e presentes, mas como uma prática social constituinte da realidade social, que modela formas de pensar e agir, define papéis sociais, generaliza posições e interpretações que se pretendem compartilhadas e universais. Como expressão de relações sociais, a imprensa assimila interesses e projetos de diferentes forças sociais que se opõem em uma dada sociedade e conjuntura e os articula segundo a ótica e a lógica dos interesses de seus proprietários, financiadores, leitores e grupos sociais que representa (MACIEL, 2004, p. 15).

O periódico $A C R U Z$ não era um veículo de comunicação voltado especialmente para as mulheres, mas nas edições do ano de 1941, inicialmente analisadas, transcorreu nas suas páginas uma expressiva preocupação da Igreja em atingir diretamente o público feminino de modo que as representações de família tradicional cristã e de sucesso produzissem efeito. Por meio da representação de família ideal, lar ideal e mulher cristã, uma realidade social foi se dando a conhecer e a construir (CHARTIER, 1990). Imagino que as ações de muitas mulheres não se restringissem apenas ao espaço privado, apesar disso, nos textos a ela direcionados prevalecia o imperativo da maternidade, quer seja nas páginas impressas desse periódico, quer em outros impressos (como a própria Fon Fon, anteriormente citada) e nos discursos da Igreja.

Qual era então o ideal de educação? Formar os homens do "Brasil de amanhã", ficava na responsabilidade da "educação doméstica", por meio da família em que a figura basilar era a mulher, a mãe cristã-católica. De outra parte, a característica enfática do discurso chamava a atenção pela força das expressões destacadas com aspas e pontos de exclamação. Como já se 
disse antes, os discursos instituíam práticas, e nesse contexto, é possível indagar: será que essas práticas ficaram adormecidas no passado?

\section{REFERÊNCIAS}

BUZATO, Gino Francisco. As transformações urbanas em Cuiabá-MT na gestão de Júlio Strübing Müller e a formação do cidadão cuiabano para a modernidade (1937-1945). Disponível em: http://sbhe.org.br/novo/congressos/cbhe7/pdf/10\%20PATRIMONIOEDUCATIVO \%20E\%20CULTURA\%20MATERIAL\%20ESCOLAR/AS\% 20TRANSFORMACOES\%20URBANAS\%20EM\%20CUIABA-MT.pdf.. Acesso em: 19 nov. 2017.

CANAVARROS, Otávio. Leitura na imprensa cuiabana: o caso de A CRUZ (1910-1940). Seminário $\mathrm{n}^{\mathrm{o}}$. 5 sobre mídia e leitura. Disponível em: http://alb.org.br/arquivomorto/edicoes_anteriores/anais16/sem05pdf/sm05ss16_05.pdf. Acesso em: 20 nov. 2017.

CASSIANO, Luiz de Carcalho. Marcha para o Oeste: um itinerário para o Estado Novo (19371945). 2002. Dissertação (Mestrado em História). Universidade de Brasília, 2002.

CASTRO, Sueli; BARROZO, João Carlos; COVEZZI, Marinete; PRETI, Oreste. a colonização oficial em Mato Grosso: a nata e a borra da sociedade. Cuiabá: EdUFMT, 2002.

CHARTIER, Roger. A História Cultural: entre práticas e representações. Rio de Janeiro: Bertrand do Brasil, 1990.

GOMES, Eslânia Fernandes. Construções Sociais do Moderno no Nordeste Brasileiro. Anais Eletrônicos do II Congresso Nacional do Cangaço e III Semana Regional de História do CFP/UFCG, 2011.

NAHES, Semiramis. Revista FON-FON: a imagem da mulher no Estado Novo (1937-1945) São Paulo: Arte \& Ciência, 2007.

ROJAS, Carlos Antonio Aguirre. Uma história dos Annales (1921-2001). Tradução de Jurandir Malerba. Maringá: Eduem, 2004.

SIMILI, Ivana Guilherme. A construção de uma personagem: a trajetória da primeira-dama Darcy Vargas (1930-1945). Disponível em: 
<http://www.fazendogenero.ufsc.br/7/artigos/I/Ivana_Guilherme_Simili_42.pdf.> Acesso em: 18 nov. 2017

ZIMMERMANN, Tânia; CARLOS, Ana Carolina Oliveira. Relações e representações de gênero no jornal A CRUZ (1910-1915), de Mato Grosso. Ciências \& Letras, Porto Alegre, n. 54, p. 4163, jul./dez. 2013. Disponível

http://seer3.fapa.com.br/index.php/arquivos/article/viewFile/190/177. Acesso em: 20 nov. 2017

Recebido em: 12 de março/2018

Aceito em: 16 de julho/2018 